\title{
Bilateral asymmetrical duplicated origin of vertebral arteries: Multidetector row CT angiographic study
}

\author{
CS Rameshbabu, OM Prakash Gupta1, Kanchan Kumar Gupta1, Muhammad Qasim¹ \\ Department of Anatomy, Muzaffarnagar Medical College, Muzaffarnagar, ${ }^{1}$ Consultant Radiologist, Dr. O.P. Gupta Imaging Center, \\ Bachcha Park, Meerut, Uttar Pradesh, India
}

Correspondence: Prof. CS Ramesh Babu, Department of Anatomy, Muzaffarnagar Medical College, Muzaffarnagar - 251203 ,

Uttar Pradesh, India. E-mail: csrameshb@gmail.com

\begin{abstract}
Bilateral duplicated origin of $\mathrm{V}-1$ segment of vertebral arteries is an extremely rare vascular variant and only two such cases have been reported so far. Presence of this vascular abnormality was observed incidentally in a 36-year-old male patient, with a complaint of dizziness, evaluated by multidetector row computed tomography (CT) angiography. Two limbs of the right vertebral artery arose from the right subclavian artery and fused to form a single vessel at the interval between fourth and fifth cervical vertebrae, which entered the foramen transversarium of fourth cervical vertebra. On the left side, the medial limb originated directly from the arch of aorta and the lateral limb from the left subclavian artery, and both united at the interval between fifth and sixth cervical vertebrae to form a single vessel which entered the foramen transversarium of fifth cervical vertebra. No other cerebrovascular pathology like aneurysm, fenestration, dissection, and stenosis was detected, which could be correlated with the symptoms of the patient. This rare congenital vascular anomaly has diagnostic and therapeutic implications in any intervention involving the vertebral artery.
\end{abstract}

Key words: Anomalous origin; bilateral duplication; dual origin; extracranial part; vertebral artery

\section{Introduction}

Knowledge of the normal and variant anatomy of the great vessels of the neck is important for endovascular interventionists and diagnostic radiologists, more so in the era of stent placements in the carotid and vertebral arteries and new therapeutic options for intracranial interventions. Unilateral duplication of the vertebral artery is rare with a reported incidence of $0.72 \%{ }^{[1]}$ Bilateral duplication of the vertebral arteries is extremely rare with two cases reported in literature. ${ }^{[2,3]}$ Dual origin of the vertebral artery usually remains silent with no clinical expression..$^{[4]}$ But it is also reported that the altered hemodynamics of the anomalous

\begin{tabular}{|l|l|}
\hline \multicolumn{2}{|c|}{ Access this article online } \\
\hline Quick Response Code: & \\
\cline { 1 - 2 } & Website: \\
\hline & www.iji.org \\
\cline { 2 - 3 } & DOI: \\
\hline & $10.4103 / 0971-3026.130699$ \\
\hline
\end{tabular}

origin may predispose a patient to certain cerebrovascular pathologies like aneurysm and dissection. ${ }^{[5-9]}$ We report here an incidental observation of bilateral duplication of the V-1 segment of the vertebral artery and to the best of our knowledge this is the third such case to be reported.

\section{Case Report}

A 36 year-old male with a history of dizziness and suspected cerebrovascular pathology was referred to our center for angiographic evaluation of carotid and vertebral arteries. He underwent multidetector 64-row computed tomography (MDCT) angiography. (GE: Optima660,2011, Tokyo, Japan60). Eighty-five milliliter of nonionic iohexolcontrast (Omnipaque, $350 \mathrm{mg} \mathrm{I} / \mathrm{ml}$, GE Healthcare, Shanghai, China) was injected at a rate of 5 $\mathrm{ml} / \mathrm{s}$ by a power injector through the antecubital vein. The acquired images (slice thickness $0.625 \mathrm{~mm}$ ) were further analyzed in a work station (GE: AW Volume Share 4) to generate volume-rendered (VR) and maximum intensity projection (MIP) images. 
The left vertebral artery (LVA) had two separate limbs of origin [Figure 1]. The medial limb (2.2 $\mathrm{mm}$ in diameter at its origin) originated directly from the aortic arch in between the origins of left common carotid (LCCA) and left subclavian arteries (LSA) [Figure 2]. The lateral limb (2.4 $\mathrm{mm}$ in diameter at its origin) emanated from the LSA in its orthodox position and entered the foramen transversarium of C6 vertebra. Both the limbs united to form a single trunk at C5-C6 interval and the single trunk (3.2 $\mathrm{mm}$ in diameter) then entered C5 transverse foramen [Figures 3 and 4]. Both the limbs of the right vertebral artery (RVA) originated from the right subclavian artery (RSA) [Figure 1]. The medial limb (3.9 mm in diameter at its origin) originated from its orthodox position, whereas the lateral limb (2.4 $\mathrm{mm}$ in diameter at its origin) arose more posteriorly close to the origin of thyrocervical trunk. The lateral limb entered the C6 transverse foramen, but the medial limb entered the carotid space lying posteromedial to right common carotid artery (CCA) [Figure 5]. At the interval between the $\mathrm{C} 4$ and $\mathrm{C} 5$ vertebrae, both the limbs fused to form a single trunk ( $4.4 \mathrm{~mm}$ in diameter) which entered the $\mathrm{C} 4$ transverse foramen [Figures 3 and 4]. Further

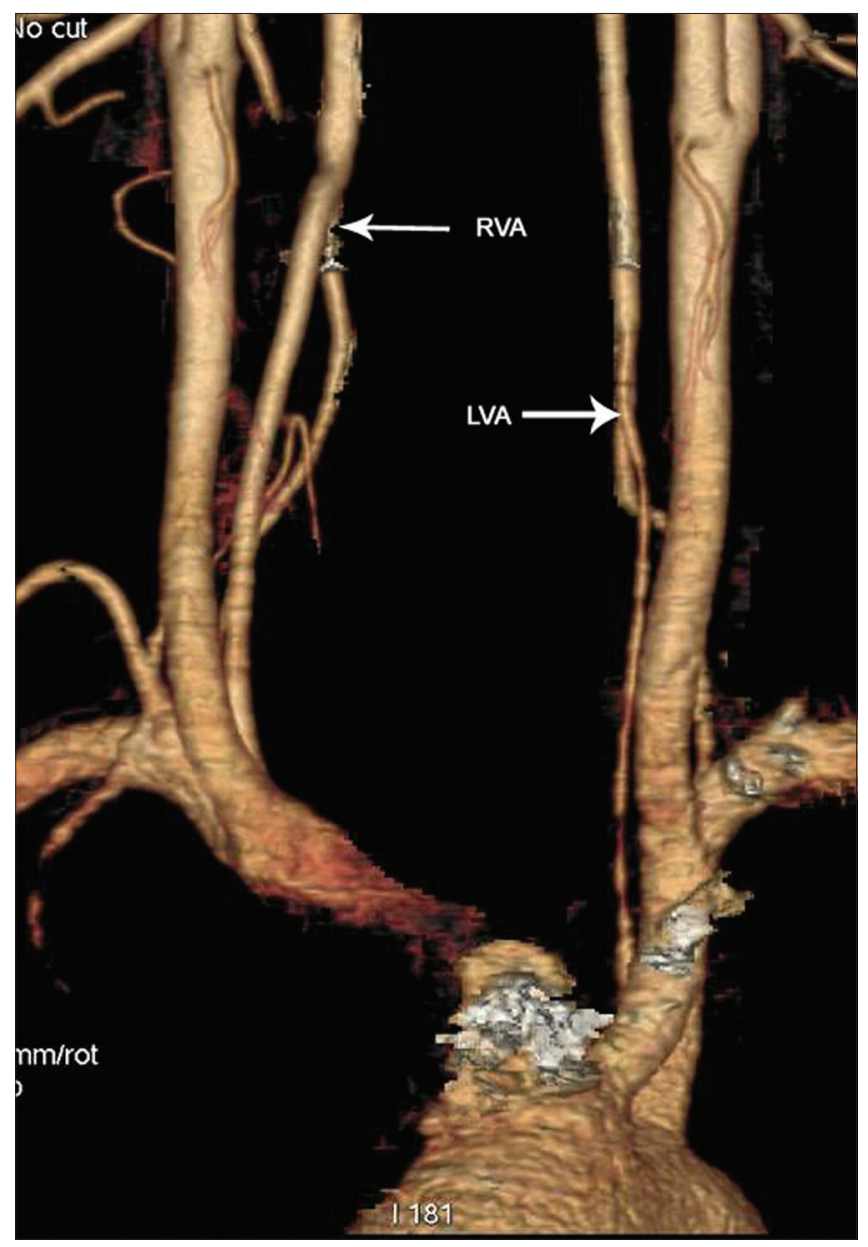

Figure 1: VR image showing duplicated origin of right vertebral artery (RVA) and left vertebral artery (LVA).The arrow indicates the level of fusion of the two limbs of the RVA and LVA distal course of both vertebral arteries was normal and no cerebrovascular pathology could be detected.

\section{Discussion}

Variations of the origin and course of the vertebral arteries are uncommon but extremely important to recognize in the diagnostic neuroradiology and for surgical and interventional procedures for treatment of patients suffering with cerebrovascular disease. One of the rarest anomalies is the duplication of the extracranial segments of the vertebral artery. ${ }^{[10]}$ The term "duplication" is strictly applied to a vertebral artery that has two origins, a variable course, and fusion level in the neck, and should not be confused with fenestration. ${ }^{[2,11]}$ Duplication occurs due to failure of involution of some embryonic vessels. ${ }^{[12]}$ Dual origin of the vertebral artery was first reported in 1844, and till 1999, about 26 cases have been reported in literature. ${ }^{[13]}$ All these cases were unilateral duplication of either right or left vertebral arteries involving the V-1 segment. Bergman et al..$^{[1]}$ noted the presence of dual origin of vertebral arteries in 5 out of 693 studied specimens $(0.72 \%)$ and incidentally all were left-sided. Unilateral duplication of the vertebral arteries was extensively reviewed, ${ }^{4,10,13,14]}$ and to the best of our knowledge, a total of about 52 cases have been reported in the published literature till date. Unilateral duplication of LVA was observed in 27 cases and RVA in 25 cases, suggesting that this anomaly is more common on the left side. Origin of both the limbs of a vertebral artery from the ipsilateral subclavian artery is more commonly observed on the right side. Both the limbs of the duplicated RVA originated from the RSA in 21 cases; origin could not be visualized in one case ${ }^{[11]}$ and

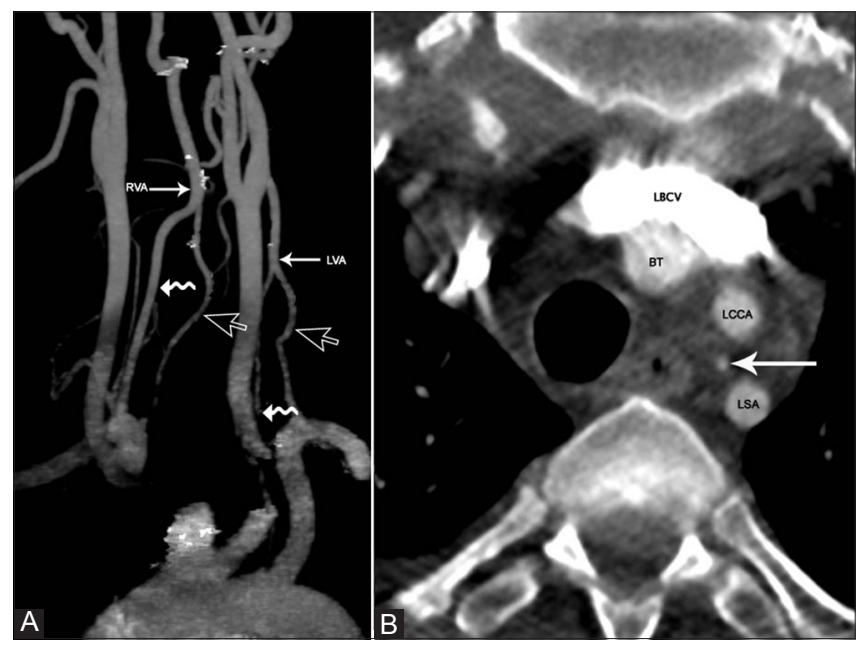

Figure 2 (A and B): MIP and axial images. (A) MIP image showing the medial limbs (curved arrow) and lateral limbs (arrow head) of both vertebral arteries. The single trunk of RVA and LVA showing the position of medial limb of LVA (arrow) between the left common carotid artery (LCCA) and the left subclavian artery (LSA). BT (brachiocephalic trunk); LBCV (left brachiocephalic vein); LVA formed is indicated by arrows. (B) Axial image at the level of third thoracic vertebra showing the position of medial limb of LVA (arrow) between LCCA and the LSA 

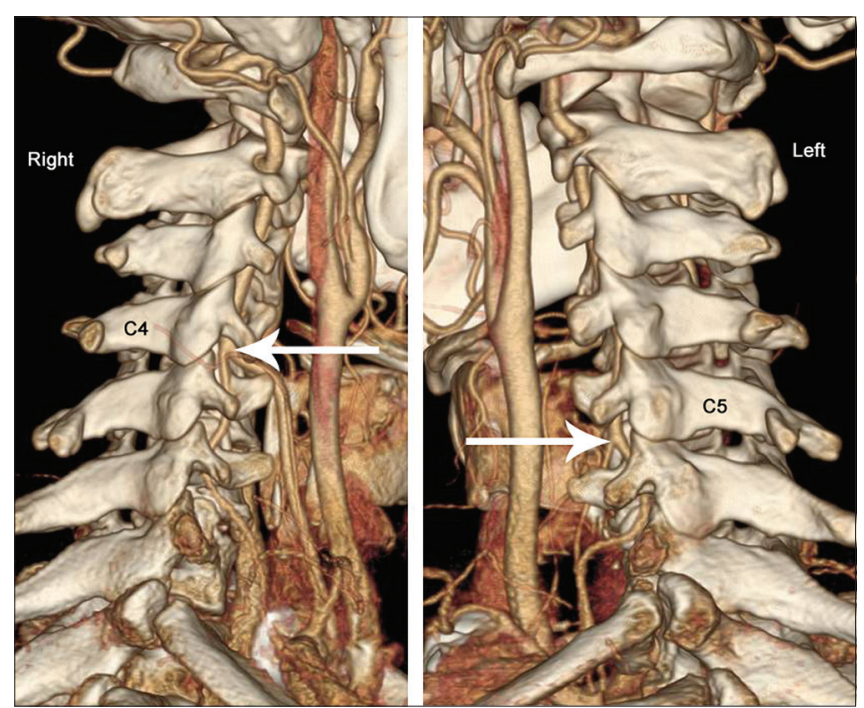

Figure 3: VR images of right lateral and left lateral views showing the level of fusion (arrow) of the two limbs of the right and left vertebral arteries. The single trunk of RVA is entering C-4 transverse foramen and the LVA entering C- 5 transverse foramen

in the rest of the three cases, one of the limbs arose from brachiocephalic trunk, aorta, or thyrocervical trunk. The pattern of origin of one limb directly from the aortic arch and the second from the subclavian is more commonly observed on the left side in 21 out of 27 cases reported. Only in three cases, both the limbs of the duplicated LVA arose from the LSA. ${ }^{[10]}$

Bilateral duplication of the V-1 segment of the vertebral artery is extremely rare and, to the best of our knowledge, only two cases have been reported so far. ${ }^{[2,3]}$ Ionete and Omojola, ${ }^{[2]}$ during the magnetic resonance (MR) angiographic evaluation of an 83-year-old man with mild cognitive impairment, observed bilateral symmetrical extracranial duplication of the vertebral artery, which they claimed to be the first report of such an anomaly. Both the limbs of each vertebral artery arose from the corresponding subclavian artery. On both sides, one limb of origin entered C7 transverse foramen and the other limb entered the carotid space. The single vertebral artery, formed by the fusion of the two limbs, entered the C4 transverse foramen on the right side and $\mathrm{C} 5$ on the left side.

During the MR angiographic evaluation of a 48-year-old man, who had suffered from a complete middle cerebral artery stroke, Mordasiniet al.$^{[3]}$ observed bilateral asymmetrical duplication of the extracranial vertebral arteries and claimed it to be the first such report. Stenosis of the proximal left internal carotid artery was also noted. In their case, one limb of LVA directly originated from the aortic arch and the other from the LSA, whereas both the limbs of RVA originated from the RSA. On both sides, one limb entered C7 transverse foramen and fused with the other limb at C4/ $\mathrm{C} 5$ interval to enter the transverse foramen of $\mathrm{C} 4$ as a single

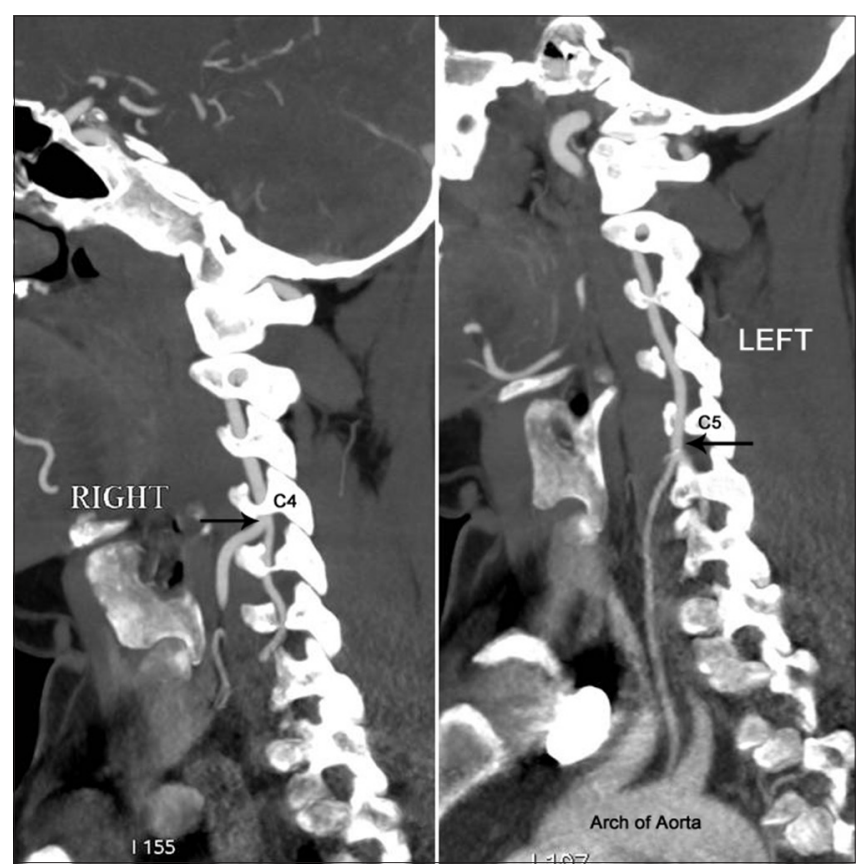

Figure 4: Sagittal MIP images showing the level of fusion of RVA at C4/C5 interval and LVA at C5/C6 interval

vertebral artery (VA). This pattern of asymmetrical origin of the two limbsof the vertebral arteries is observed in the present case also, but the level of fusion differs.

The embryogenesis of the vertebral artery begins at approximately 32 days and is completed by 40 days. In the cervical region, seven intersegmental arteries connected proximally to primitive dorsal aortae develop. Each intersegmental artery divides into dorsal and ventral branches. Longitudinal plexiform anastomotic channels link the cervical intersegmental arteries with each other and are named according to their position as precostal anastomosis, postcostal anastomosis, and posttransverse anastomosis. The proximal connections between the first six cervical intersegmental arteries and the dorsal aortae regress and the first six intersegmental arteries involute. On each side, the seventh intersegmental artery enlarges to form the proximal part of the subclavian artery including the point of origin of the vertebral artery. The dorsal branch of the seventh intersegmentalartery remains as the first part ( $\mathrm{V}-1$ segment) of the vertebral artery and the postcostal anastomosis between C6 and C1 vertebrae develops into second part of the artery. ${ }^{[2,3,10]}$ Sim et al. ${ }^{[15]}$ had stated that a portion of the primitive dorsal aortae may not regress along with one or two intersegmental arteries that are connected to the vertebral artery. Duplication of the vertebral artery results from failure of controlled regression of the right or left fourth, fifth, or sixth intersegmental artery.

Although there is no conclusive evidence that VA duplication has any etiopathologic association with cerebrovascular disease, anecdotal reports describe clinical symptoms such 


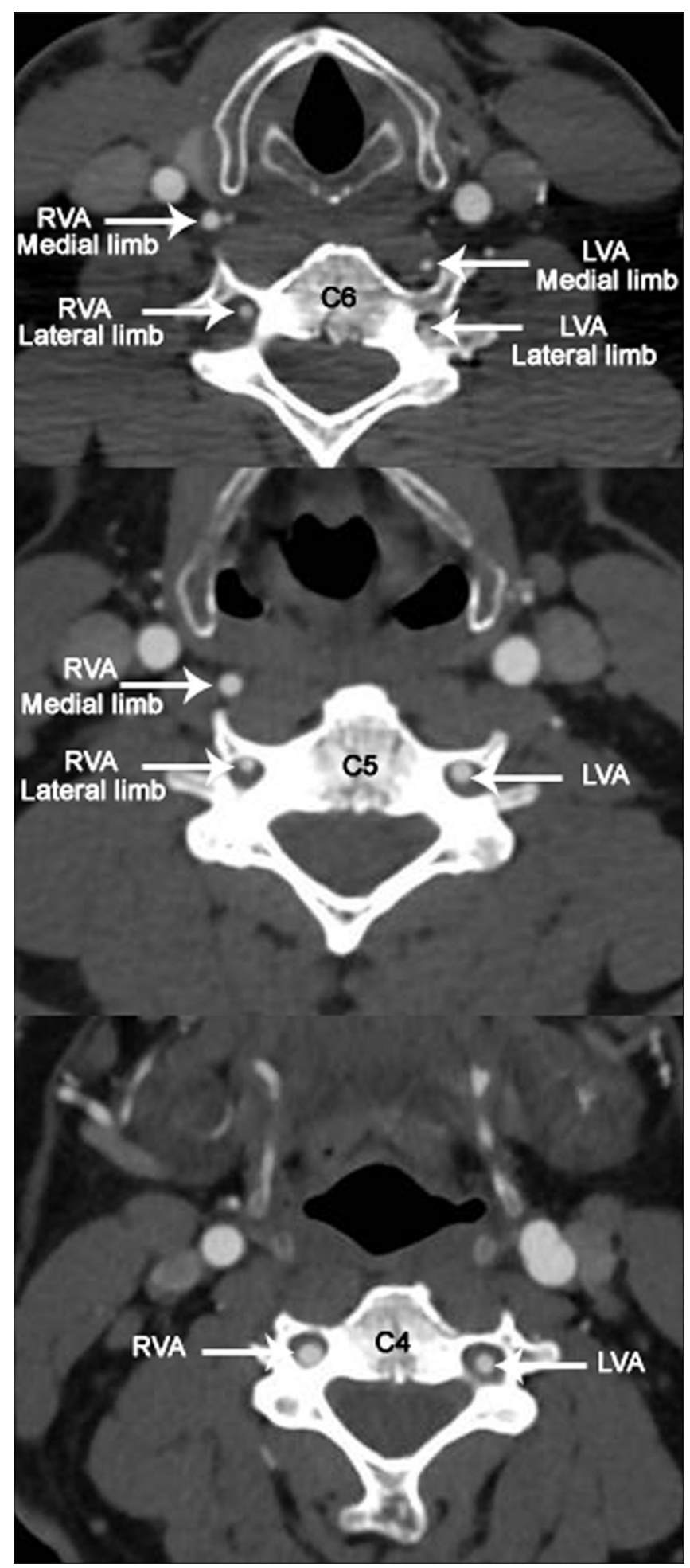

Figure 5: Axial images at the level of C4, C5, C6 vertebrae showing the medial and lateral limbs of both vertebral arteries. Note the position of medial limb of RVA in the carotid space, lying posteromedial to common carotid artery

as dizziness or vertigo in patients with anomalous origin of VA. ${ }^{[3,16]}$ It has been suggested that duplicated origin of the VA may lead to altered hemodynamics and predispose a patient to certain cerebrovascular pathologies like fenestration, aneurysm, dissection, kinking, and arteriovenous malformations. ${ }^{[5-9,17,18]}$ It has been proposed that distinct histological features of the two limbs of the duplicated VA may result in altered hemodynamics, but no such evidence was found in a cadaveric study on RVA duplication. ${ }^{[19]}$

In conclusion, we have presented our observations on a very rare vascular variation of bilateral asymmetrical duplication of extracranial V-1 segment of the vertebral artery. We consider prospective reporting of such anomalies has significant clinical and surgical implications during endovascular interventional and neurosurgical reconstructive procedures. Failure to recognize such vascular variants might result in misdiagnosis leading to unwarranted and avoidable therapeutic interventions.

\section{Acknowledgments}

The authors gratefully acknowledge the technical assistance rendered by Mr. Arjun Singh, Radiology Technician and Mr. Tithender, Photographer

\section{References}

1. Bergman RA, Thompson SA, Afifi AK, Saadeh FA. Compendium of human anatomic variation: Text, atlas and world literature. Baltimore: Urban and Schwarzenberg; 1988. p. 71-2, 358-9.

2. Ionete $\mathrm{C}$, Omojola MF. MR angiographic demonstration of bilateral duplication of the extracranial vertebral artery: Unusual course and review ofthe literature. AJNR Am J Neuroradiol 2006;27:1304-6.

3. Mordasisni P, Schmidt F, Schroth G, Remonda L. Asymmetrical bilateral duplication of the extracranial vertebral arteries: Report of a unique case. Eur J Radiol Extra2008;67:e91-4.

4. Takasato Y, Hayashi H, Kobayashi T, Hashimoto Y. Duplicated origin of right vertebral artery with rudimentary and accessory left vertebral arteries. Neuroradiology 1992;34:287-9.

5. Dare AO, Chaloupka JC, Putman CM, Meyer PL, Schneck MJ, Fayad PB. Vertebrobasilar dissection in a duplicated cervical vertebral artery: A possible pathoetiologic association? A case report. Vasc Endovascular Surg 1997;31:103-9.

6. Satti SR, Cerniglia CA, Koenigsberg RA. Cervical vertebral artery variations: An anatomic study.AJNR Am J Neuroradiol 2007;28:976-80.

7. Thomas AJ, Germanwala AV, Vora N, Prevedello DM, Jovin T, Kassam A, et al. Dual origin extracranial vertebral artery: Case report and embryology. J Neuroimaging 2008;18:173-6.

8. Kendi AT, Brace JR. Vertebral artery duplication and aneurysms: 64 slice multidetector CT findings. Br J Radiol 2009;82:e216-8.

9. Melki E, Nasser G, Vandendries C, Adams D, Ducreux D, Denier C. Congenital vertebral duplication: A predisposing risk factor for dissection. J Neurol Sci 2012;314:161-2.

10. Polguj M, Jędrzejewski K, Topol M, Wieczorek-Pastusiak J, Majos A. Duplication of left vertebral artery in a patient with dissection of the right internal carotid artery and Ehlers-Danlos syndrome: Case report and review of the literature. Anat Sci Int 2013;88:109-14.

11. Goddard AJ, Annesley-Williams D, Guthrie JA, Weston M. Duplication of the vertebral artery: Report of two cases and review of the literature. Neuroradiology 2001;43:477-80.

12. Harnier S, Harzheim A, LimmrothV, Horz R, Kuhn J. Duplication of the common carotid artery and the ipsilateral vertebral artery 
with a fenestration of the contralateral common carotid artery. Neurol India 2008;56:491-3.

13. Komiyama M, Nakajima H, Yamanaka K, Iwai Y. Dual origin of the vertebral artery-Case report. Neurol Med Chir (Tokyo) 1999;39:932-7.

14. Lemke AJ, Benndorf G, Liebig T, Felix R. Anomalous origin of the right vertebral artery: Review of the literature and case report of right vertebral artery origin distal to the left subclavian artery. AJNR Am J Neuroradiol 1999;20:1318-21.

15. Sim E, Vaccaro AR, Berzlanovich A, ThalerH, Ullrich CG. Fenestration of the extracranial vertebral artery: Review of the literature. Spine (Phila Pa 1976) 2001;26:E139-42.

16. Shin SW, Park DW, Park CK, Lee YJ, Lee SR. Duplication of the left vertebral artery origin: A case report. J Korean SocRadiol 2013:68:1-4.
17. Kim DW. Concomitant dual origin and fenestration of the left vertebral artery resembling dissection. J Korean Neurosurg Soc 2009;46:498-500.

18. Komiyama M, Morikawa T, Nakajima H, Nishikawa M, Yasui T. High incidence of arterial dissectionassociated with left vertebral artery of aortic origin. Neurol Med Chir (Tokyo) 2001;41:8-11; discussion 11-2.

19. Rath G, Prakash R. Double vertebral artery in an Indian cadaver. Anat Clin 1984;6:117-9.

Cite this article as: Rameshbabu CS, Gupta OP, Gupta KK, Qasim M. Bilatera asymmetrical duplicated origin of vertebral arteries: Multidetector row CT angiographic study. Indian J Radiol Imaging 2014;24:61-5.

Source of Support: Nil, Conflict of Interest: None declared. 